\title{
ELEITORALISMO E OLIGARQUIZAÇÃO DA DEMOCRACIA: REFLEXÕES SOBRE O USO DO SORTEIO COMO GARANTIA DO IDEAL REPUBLICANO DA NÃO- DOMINAÇÃO
}

\section{ELECTORALISM AND THE OLIGARCHIZATION OF DEMOCRACY: THE USE OF LOT AS A GUARANTEE OF THE REPUBLICAN IDEAL OF NON-DOMINATION}

\author{
Rodrigo Ribeiro de Sousa ${ }^{1}$
}

\section{RESUMO}

Nos últimos anos, o "mal-estar" da população mundial com as regras e resultados da democracia representativa tornou-se um fato público e notório em grande parte das democracias do mundo. A corrupção do sistema político, as dificuldades de superação das desigualdades sociais e a incapacidade de inclusão das minorias refletem um domínio persistente das elites políticas, incompatível com os valores democráticos e republicanos. Partindo da constatação dos limites práticos dos governos representativos contemporâneos, de modo geral, e da democracia representativa brasileira, em particular, o propósito do artigo é o de debater em que medida a reintrodução do elemento do sorteio em nossas práticas políticas pode contribuir para uma reabilitação dos valores democráticos, promover a inclusão social e favorecer a implementação da liberdade como não-dominação, nos termos da formulação de Philip Pettit. Para tanto, serão abordadas referências teóricas recentes no campo das denominadas "inovações democráticas", em especial a perspectiva de "democracia aberta", de Hélène Landemore. A metodologia empregada é essencialmente a análise bibliográfica dos textos estudados.

Palavras-chave: democracia; sorteio; igualdade política; eleitoralismo; republicanismo.

\begin{abstract}
In recent years, the "malaise" of the world population with the rules and results of representative democracy has become a public and notorious fact in most democracies in the world. The corruption of the political system, the difficulties in overcoming social inequalities and the inability to include minorities reflect a persistent dominance of political elites, incompatible with civic-democratic values. Based on the observation of the practical limits of contemporary representative governments, in general, and of Brazilian representative democracy, in particular, the purpose of the article is to debate to what extent the reintroduction of the lot in our political practices may contribute to a rehabilitation of democratic values, promote social inclusion and favor the implementation of freedom as non-domination, in terms of the formulation of Philip Pettit. To achieve this purpose, recent theoretical references in the field of the so-called "democratic

\footnotetext{
1 Professor Doutor da Faculdade de Ciências Aplicadas (FCA) da Universidade Estadual de Campinas (UNICAMP). Membro titular da Comissão de Pesquisa (CPesq) da unidade (2019-2021), membro titular do Núcleo Docente Estruturante (NDE) do curso de Administração Pública (2019-presente), membro suplente da Comissão de Extensão (Cext) da FCA, membro da Comissão de Assessora para Inclusão Acadêmica e Participação dos Povos Indígenas (CAIAPI), da UNICAMP. Integrante do Laboratório de Estudos do Setor Público (LESP) da UNICAMP, membro dos grupos de pesquisa do CNPq "Matrizes do Republicanismo" e "Res publica" e do Grupo de Trabalho (GT) "Direito e Filosofia", da Associação Nacional de Pós-Graduação em Filosofia (ANPOF). Afiliação: Universidade Estadual de Campinas - UNICAMP. Lattes:http://lattes.cnpq.br/1957563294350061. ORCID: https://orcid.org/0000-0002-9531-2255. E-mail: rrsousa@unicamp.br
} 
innovations" will be addressed, in particular the perspective of "open democracy", by Hélène Landemore. The methodology adopted is bibliographic analysis.

Keywords: democracy; lot; political equality; electoralism; republicanism.

\section{INTRODUÇÃO}

Nos últimos anos, o "mal-estar" da população mundial com as regras e resultados da democracia representativa tornou-se um fato público e notório em grande parte das democracias do mundo. A corrupção do sistema político, as dificuldades de superação das desigualdades sociais e a incapacidade de inclusão das minorias - ou mesmo de maiorias, como no caso brasileiro - refletem um domínio persistente das elites políticas, incompatível com os valores republicanos e democráticos. No Brasil, por exemplo, embora, segundo dados do Instituto Brasileiro de Geografia e Estatística (IBGE) ${ }^{2}$, as pessoas negras representem $55,8 \%$ da população, apenas $24,4 \%$ dos deputados federais são negros, o que dificulta - e, em muitos casos, inviabiliza - a realização do ideal republicano de não-dominação, nos termos da formulação de Philip Pettit.

Em busca de soluções para o peculiar problema da sub-representação de setores majoritários da sociedade brasileira nos cargos eletivos dos Poderes Legislativo e Executivo, o Supremo Tribunal Federal (STF) - e não o parlamento - tomou, com fundamento no princípio constitucional da igualdade, entre os anos de 2018 e 2020, duas importantes decisões. A primeira, delas, proferida em março de 2018 no âmbito da Ação Declaratória de Inconstitucionalidade (ADI) n 5.617, estabeleceu aos partidos políticos uma cota mínima de 30\% (trinta por cento) de candidaturas de mulheres para os cargos majoritários e proporcionais, acompanhada da atribuição, na mesma proporção, dos valores do Fundo Eleitoral destinado a promovê-las. A segunda, tomada no bojo da Arguição de Descumprimento de Preceito Fundamental (ADPF) $n^{\circ} 738$, julgada em outubro de 2020, determinou a concessão de incentivos a candidaturas de pessoas negras, ao estipular a divisão dos recursos públicos do Fundo Partidário e do Fundo eleitoral de forma proporcional ao número de candidaturas de negros e negras, bem como a divisão proporcional do tempo de propaganda no rádio e na televisão, na exata proporção das candidaturas de negros e não negros em cada partido.

Por meio de tais decisões, foram estabelecidos, portanto, percentuais mínimos de candidaturas femininas a serem registradas por cada partido político, com a aplicação proporcional dos recursos do fundo destinado ao financiamento das campanhas de mulheres (ADI $\mathrm{n}^{\circ}$ 5617), além

\footnotetext{
${ }^{2} \mathrm{O}$ índice é resultante da soma dos valores de pretos e pardos, de acordo com os critérios estabelecidos pelo IBGE. Fonte: Instituto Brasileiro de Geografia e Estatística (IBGE). Pesquisa Nacional por Amostra de Domicílios Contínua, 2018. Disponível em https://www.ibge.gov.br/estatisticas/sociais/populacao/25844-desigualdadessociais-por-cor-ou-raca.html. Acesso em 24 de junho de 2021.
} 
da equidade na destinação dos recursos e do tempo de propaganda entre candidatos brancos e negros $\left(\mathrm{APDF} \mathrm{n}^{\circ} 738\right)$.

Em que pese a grandeza dos propósitos da Suprema Corte ao proferir tais decisões, as medidas adotadas não tiveram, no entanto, o efeito prático almejado.

De fato, nas eleições municipais de 2020, de acordo com dados do Tribunal Superior Eleitoral (TSE) $)^{3}$ embora as mulheres representem 52,5\% do eleitorado, apenas $16 \%$ dos cargos de vereador foram preenchidos por mulheres (ante 13,5\% nas eleições de 2016) e 12,2\% dos cargos de prefeito (ante 11,5\% em 2016). Dentre as capitais, apenas uma cidade é governada por uma mulher (Palmas, capital do Estado do Tocantins).

Quanto às pessoas negras, que representam aproximadamente $56 \%$ da população brasileira, apenas $32 \%$ do total de prefeituras (ante $29 \%$ nas eleições de 2016) e $44 \%$ do total de postos de vereadores (ante $42 \%$ nas eleições anteriores) ${ }^{4}$ foram ocupados, nas mesmas eleições, por negros ou negras.

Para piorar, nas eleições de 2018 e 2020, em que vigoraram as novas regras fixadas pelo Supremo Tribunal Federal (STF), surgiram inúmeras denúncias de candidaturas fraudulentas de mulheres (algumas das quais obtiveram pouquíssimos ou até mesmo nenhum voto, e chegaram a fazer abertamente campanhas para outros candidatos), evidenciando a ocorrência de fraudes na cota de candidaturas femininas, em um escândalo que ficou conhecido como "escândalo das candidaturas laranjas"

Uma parte relevante do problema parece estar no domínio das siglas partidárias por pequenos grupos que se apropriam da "máquina" interna dos partidos, formando uma oligarquia partidária da qual depende todo o funcionamento do sistema representativo brasileiro. Essa elite burocrática interna, presente em praticamente todos os 33 partidos atualmente ativos no Brasil, dificulta a renovação política e subordina o reconhecimento das candidaturas a uma série de "troca de favores", que retroalimenta as práticas de dominação e perpetua no poder as mesmas elites, que, não raro, ostentam os mesmos sobrenomes de políticos tradicionais, há muito conhecidos no país, formando espécies de "dinastias partidárias".

Tal prática é favorecida, vale dizer, pela previsão, no sistema eleitoral brasileiro, da filiação partidária obrigatória como condição de elegibilidade (art. $14, \S 3^{\circ}$, inciso $\mathrm{V}$, da Constituição da República), o que impede a formalização de candidaturas livres ou avulsas no país, apresentadas fora da estrutura partidária.

\footnotetext{
${ }^{3}$ Cf. https://www.tse.jus.br/eleicoes/estatisticas/estatisticas-eleitorais. Acesso em 24 de junho de 2021.

${ }^{4}$ Idem nota 2.

${ }^{5}$ Cf.https://www.correiobraziliense.com.br/politica/2020/11/4891306-eleicoes-mp-investiga-denuncias-decandidaturas-laranjas-de-mulheres.html. Acesso em 24 de junho de 2021.
} 
Em um caso de tamanha sub-representação, no qual setores majoritários da sociedade são governados sistematicamente por setores minoritários, como garantir que o ideal de não-dominação seja assegurado? Como evitar a evidente "oligarquização da democracia”?

Partindo da constatação dos limites práticos da democracia representativa brasileira, o propósito deste artigo é o de debater em que medida a recuperação da prática do sorteio - elemento fundamental na história da democracia e do pensamento republicano -pode contribuir para uma reabilitação dos valores democráticos, promover a inclusão social e favorecer a implementação da liberdade como não-dominação, nos termos da formulação de Philip Pettit.

\section{SORTEIO E ISONOMIA: A RELAÇÃO ENTRE SORTEIO E DEMOCRACIA NA HISTÓRIA DO PENSAMENTO POLÍTICO}

Inicialmente, é fundamental registrar o pressuposto teórico adotado neste artigo no tocante à relação entre o pensamento democrático e o republicanismo. Seguindo Bill Brugger (BRUGGER, 1999, p. 146) e Newton Bignotto, partimos da compreensão de que o republicanismo, diversamente da tradição liberal, exige a democracia e dela faz parte, de modo que a escolha de quais aspectos da tradição devem ser reapropriados deve ser compatível com essa crença (BIGNOTTO, 2004, p. 20). Dessa forma, a reflexão sobre a democracia faz parte do universo conceitual republicano e sua compreensão, no âmbito da formulação teórica de cada um dos autores estudados, integra o amplo conjunto de indagações republicanas acerca do melhor regime político.

A reflexão sobre os problemas democráticos contemporâneos exige, nesse sentido, a recuperação de algumas das principais referências teóricas sobre a democracia. Ora, como sabemos, desde a antiguidade, o traço distintivo da democracia é o sorteio, por permitir a expressão máxima da igualdade política, ao proporcionar a isonomia, a isocracia e a isegoria, fundamentos desse regime político. É o que afirma expressamente Aristóteles, ao tratar, no Livro IV, parte 9, da Política, da formação dos regimes mistos ou constitucionais:

\footnotetext{
Um terceiro modo [de compor o regime misto] é uma combinação de disposições de ambos os regimes, umas extraídas da lei oligárquica, e outra da democrática. Refiro, por exemplo, o caso das magistraturas: o sorteio para ocupação dos cargos públicos parece mais conforme ao espírito democrático, enquanto a eleição parece ser mais adequada ao espírito oligárquico (ARISTÓTELES, 1998, p. 305-306).
}

De fato, como destaca David Reybrouck, a democracia ateniense utilizou amplamente, em seu apogeu, entre os séculos V a.C. e IV a.C., do sorteio para preenchimento dos cargos componentes dos órgãos de governo da pólis, sendo a escolha aleatória de cidadãos utilizada para as funções legislativas, executivas e judiciárias. Assim, por exemplo, a lei era elaborada pelo Conselho dos Quinhentos (a Boulé), cujos membros eram sorteados, e votada pela assembleia 
popular (Eklésia). O tribunal popular (Helieia), formado por cidadãos sorteados, examinava a legalidade da nova lei, e os magistrados (Arkhai), que eram em parte sorteados e em parte eleitos, a executavam (REYBROUCK, 2017, p. 114). Quanto aos magistrados, de um total de setecentos cargos existentes, seiscentos eram escolhidos por sorteio. Apenas os postos que demandavam conhecimentos técnicos, como as magistraturas militares e as de arquitetura eram eleitos pelo Conselho dos Quinhentos, sendo a maior parte das magistraturas, portanto, ocupadas por sorteio (REYBROUCK, 2017, p. 113-114).

Para a efetivação do sorteio, os atenienses utilizavam, como descreve M. H. Hansen, um aparato denominado kleroterion, uma superfície de mármore, da altura aproximada de um homem, com encaixes para fichas, que eram dispostas em cinco colunas. Em cada um desses encaixes, os candidatos a um determinado cargo, como o de jurado do tribunal ou membro do Conselho dos Quinhentos, por exemplo, inseriam uma espécie de ficha, denominada pinakion, na qual estava grafado seu nome. Bolinhas coloridas eram inseridas em um tubo metálico colocado na parte lateral do kleroterion, no sentido vertical. Na medida em que as bolas eram sorteadas, excluíam-se ou escolhiam-se os nomes de uma determinada linha, de acordo com a cor da bolinha sorteada. Se a bola fosse branca, todos os cinco cidadãos cujas fichas estavam dispostas em uma linha horizontal do kleroterion eram selecionados; se a bola fosse preta, os cinco cidadãos da retiravam suas fichas e estavam dispensados (HANSEN, 1991, p. 198).

Por meio desse engenhoso - posto que relativamente simples - sistema, cidadãos sorteados ocupavam, portanto, o centro do poder político na democracia ateniense. O sorteio era utilizado com o claro objetivo de favorecer a igualdade política entre os cidadãos ${ }^{6}$. Desse modo, além do exercício direto do poder no âmbito da Eklésia, a democracia ateniense utilizou amplamente, no período clássico, uma combinação de sorteio e eleição, edificando assim um governo misto que permitia grande legitimidade e eficiência ao sistema político.

Além da democracia ateniense, a república romana também manteve, como observa Reybrouk, resquícios do sistema ateniense do sorteio, que embora tenha caído em desuso no período do Império, voltou a ser utilizado nas cidades livres do norte da Itália durante a Idade Média. Bolonha, Vicenza e Pisa possuem exemplos da adoção, em alguma medida, da prática do sorteio para escolha de cargos políticos, mas os casos mais bem documentados no período são os de

\footnotetext{
${ }^{6}$ É sempre importante recordar o caráter limitado e exclusivista da democracia ateniense, que não atribuía a condição de cidadãos aos menores, às mulheres, aos escravos e aos estrangeiros, reduzindo o direito de participação política a um percentual bastante limitado de cidadãos, que representavam apenas cerca de 15\% (quinze por cento) da população total (GOMME, 1933). A despeito disso, a reflexão quanto aos fundamentos da isonomia, da isocracia e da participação política na Atenas clássica pode nos apresentar importantes elementos de questionamento das práticas políticas vigentes nas democracias contemporâneas.
} 
Florença e Veneza, tendo a sereníssima república utilizado por séculos o sorteio como critério fundamental para a escolha do Doge (REYBROUCK, 2017, p. 119-121).

Do ponto de vista da história das ideias políticas, a centralidade do sorteio como elemento democrático foi igualmente reconhecida na modernidade. Montesquieu, por exemplo, ao tratar, no capítulo II, do livro segundo, d' $O$ espírito das leis, acerca do governo republicano e das leis relativas à democracia, apresenta raciocínio semelhante ao de Aristóteles, ao sustentar que:

O sufrágio pelo sorteio é da natureza da democracia; o sufrágio pela escolha é da natureza da aristocracia.

O sorteio é uma maneira de eleger que não aflige ninguém: deixa a cada cidadão uma esperança razoável de servir sua pátria.

Mas, como é defeituoso por si, foi em sua regulamentação e em sua correção que os grandes legisladores se superaram.

Sólon estabeleceu em Atenas que se nomearia por escolha para todos os cargos militares e que os senadores e os juízes seriam eleitos por sorteio.

(MONTESQUIEU, 2000, p. 22).

Embora reconhecesse a existência de problemas caso a escolha das magistraturas fosse realizada exclusivamente por sorteio, Montesquieu observa a importância do sorteio para a realização da natureza da democracia, ainda que, de modo semelhante ao empreendido em Atenas pela ação dos grandes legisladores, tal prática devesse ser regulada por "leis fundamentais", que restringissem a sua amplitude e mantivessem as eleições para alguns cargos, em uma equilibrada combinação entre o sufrágio por sorteio e o por escolha.

Rousseau, por sua vez, embora sustente que a democracia não é compatível com a ideia de representação - na medida em que esta é compreendida pelo filósofo como uma espécie de delegação e a vontade geral, que expressa a soberania, não está sujeita a transferência -, por outro lado, ao tratar da administração do Estado nas repúblicas, o genebrino também identifica no sorteio o elemento central da "verdadeira democracia", admitindo a noção de representação para essa finalidade. Concordando expressamente com Montesquieu quanto à natureza democrática do sorteio, sustenta o autor do Contrato Social:

Se considerarmos que a eleição dos chefes é uma função do governo e não da soberania, veremos por que o expediente do sorteio está mais na natureza da democracia, na qual a administração é tanto melhor quanto menos multiplicados são os atos.

Em qualquer verdadeira democracia, a magistratura não é uma vantagem, mas uma carga onerosa que não se pode, com justiça, impor mais a um particular que a outro. Só a lei pode impor essa carga a quem o sorteio indicar, pois, nesse caso, sendo a condição igual para todos, e não dependendo a escolha de nenhuma vontade humana, não há aplicação particular que altere a universalidade da lei. (...)

As eleições por sorteio apresentariam poucos inconvenientes em uma verdadeira democracia, onde, sendo todos iguais, quer pelos costumes e talentos, quer pelos preceitos e pela fortuna, a escolha se tornaria indiferente. Mas, como já afirmei, não existe verdadeira democracia. (ROUSSEAU, 1999, p. 132-133) 
Embora identifique a inexistência concreta de uma verdadeira democracia, na medida em que, em todas as sociedades, os talentos e capacidades são divididos de modo desigual, Rousseau sustenta que isso não significa que devamos abrir mão do sorteio, mas sim procurar um modo equilibrado, intermediário entre o sorteio e a eleição:

Quando a escolha e o sorteio se combinam, a primeira deve preencher os postos que exigem talentos apropriados, como os cargos militares; o segundo convém aos postos que requerem apenas bom senso, justiça e integralidade, como os casos de judicatura, porque, num Estado bem constituído, tais qualidades são comuns a todos os cidadãos. (ROUSSEAU, 1999, p. 133)

Mas, se filósofos tão influentes para a formação dos Estados de Direito contemporâneos, como Montesquieu e Rousseau, foram enfáticos defensores de um regime misto, resultante da combinação do sorteio e das eleições, por qual razão as democracias contemporâneas afastaram por completo a prática de nomeação de governantes por sorteio, menos de uma geração após a publicação d' O espírito das leis e Do contrato social, substituindo-a por sistemas representativos baseados quase exclusivamente na realização de eleições? Como observa Bernard Manin, o sorteio foi totalmente ignorado durante a Revolução Americana e no curso da Revolução Francesa, sendo que tanto de um lado do Atlântico como do outro, estabeleceu-se, sem a menor hesitação, uma limitação dos direitos políticos dos cidadãos por meio da instituição de sistemas de escolha notadamente aristocráticos (MANIN, 2012, p. 108).

Embora o triunfo unilateral das eleições após as grandes revoluções do século XVIII - tanto no caso da Revolução Francesa quanto no da Revolução Americana - possa ser explicado por diferentes razões, como a grande extensão territorial das repúblicas contemporâneas em comparação com as pólis gregas e as cidades livres italianas, por exemplo, ou mesmo pelo desconhecimento teórico da prática política da democracia ateniense, o principal motivo da adoção de um regime aristocrático baseado exclusivamente em eleições em ambos os países deve ser considerado, como destaca Reybrouck, o total desinteresse dos revolucionários da França e dos Estados Unidos em estabelecer uma verdadeira democracia, em razão da grande desconfiança em relação ao povo e do medo do estabelecimento de uma "tirania da maioria” (REYBROUCK, 2017, p. 137-138).

O propósito de promover uma neutralização política do povo constituiu-se, nesse sentido, como o grande projeto das elites que instituíram as primeiras repúblicas contemporâneas, que foram fundadas com o objetivo de estabelecer uma clara distinção entre os cidadãos ilustres - destinados a governar - e os eleitores - destinados a serem governados - que foram significativamente privados 
de uma participação efetiva nas decisões públicas, ao serem confinados a um envolvimento episódico e superficial, restrito ao solitário momento do voto.

\title{
3. ELEITORIALISMO E OLIGARQUIZAÇÃO DA DEMOCRACIA: A MITIGAÇÃO DO SORTEIO NOS GOVERNOS REPRESENTATIVOS CONTEMPORÂNEOS
}

De fato, como destaca Hélène Landemore, os governos representativos contemporâneos foram originalmente concebidos como formas de governo de elite em contraste com o governo dos cidadãos comuns. Entre os "pais fundadores" da nação americana, James Madison, em particular, temia a tirania da maioria tanto quanto ele rejeitava as antigas ordens monárquicas. Mas o mais importante para Madison é que a república americana fosse caracterizada, em contraposição às antigas democracias, pelo afastamento do povo da participação no governo. A república arquitetada pelos fundadores deveria ser fundada, assim, não no poder do povo, mas sim no poder das elites eleitas (LANDEMORE, 2020, p. 3-4).

É o que afirmam os autores d'O federalista, ao defender, no artigo LXIII, a instituição de um senado como forma de refrear os ânimos do povo contra a tirania de suas próprias paixões:

\begin{abstract}
Assim como nos governos livres a opinião serena e ponderada da comunidade deve, em última instância, prevalecer sobre as ideias de seus governantes, também há momentos especiais nos negócios públicos em que o povo, estimulado por uma paixão anormal, ou uma vantagem ilícita, ou iludido pelos embustes ardilosos de homens de má-fé, pode reclamar medidas que mais tarde ele próprio não hesitará em lamentar e condenar. Nesses momentos críticos, será salutar a interferência de um corpo moderado e respeitável de cidadãos, para deter essa corrida desorientada e evitar a desgraça que o povo prepara para si próprio, até que a razão, a justiça e verdade possam recuperar seu poder sobre o espírito do povo. De quanta angústia pungente o povo de Atenas não teria sido poupado seu governo se seu governo contivesse tão prudente salvaguarda contra a tirania de suas próprias paixões? (HAMILTON, MADISON e JAY, 1987, p. 406)
\end{abstract}

Os fundadores da república americana defendiam explicitamente, nesse sentido, um regime em que a competência e a virtude dos líderes eram centrais, no qual o talento e a sabedoria das elites eleitas deveriam ser capazes de "refinar" as opiniões do povo, que era considerado passional e irracional. Em tal sistema, a representação política seria naturalmente concebida como um filtro capaz de afastar os cidadãos comuns da prática política imediata e de atribuir as funções de governo a um grupo social e economicamente homogêneo, edificando um regime que seria considerado por seus críticos, desde a sua origem, como uma "aristocracia natural" (LANDEMORE, 2020, p. 40).

Concebida com o objetivo de assegurar a dominação de uma elite sobre as demais partes do corpo político e com um compromisso meramente retórico com o poder do povo, a república americana afastou por completo de suas instituições a prática do sorteio, na medida em que esta 
destina-se justamente a assegurar a igualdade política que seus fundadores tanto almejavam combater.

A engenhosidade desse ato de fundação residiu, assim, como destaca Landemore, no fato de que a característica central e distintiva do novo regime não foi apresentada como se tratando da construção de uma oligarquia em oposição a uma democracia, mas sim de um governo "representativo" em detrimento de um governo "direto". A consequência dessa ênfase foi justamente sugerir que o governo da elite era uma solução necessária para o problema do tamanho, e de que a representação deve implicar necessariamente eleições. Esse "deslocamento semântico" escondeu por completo das gerações futuras a existência de outra possibilidade conceitual, há muito conhecida do pensamento republicano, qual seja, o governo representativo exercido de forma indireta por cidadãos comuns, escolhidos total ou parcialmente por sorteio (LANDEMORE, 2020, p. 4).

Embora mencionassem diversas vezes a noção de governo popular, dando a entender que estavam a defender o ideal da soberania popular, os pais fundadores da nação americana visaram, na verdade, como sustenta Landemore, instituir um governo representativo liberal, impondo, para promover a exclusão do povo, uma clara barreira de poder, que impede que essa forma de governo possa ser interpretada como uma "democracia". Como salienta a autora, essa noção continua a ecoar no presente por meio de diferentes metáforas que dominam as teorias políticas contemporâneas. É o caso, por exemplo da noção de "razão pública" de John Rawls, que poderia ser institucionalizada na Suprema Corte dos Estados Unidos, mas que nada mais é do que um grupo de cidadãos considerados como possuidores de "mentes superiores", supostamente imunes a pressões políticopartidária e capazes de se posicionar acima da disputa, falando em termos desapaixonados e emitindo decisões essencialmente contramajoritárias (LANDEMORE, 2020, p. 4-5).

Tal concepção tem de ser tomada, no entanto, como um produto de seu tempo, e não está mais em sintonia, como observa Landemore, com as expectativas democráticas contemporâneas. As interpretações de Cortes Supremas são visivelmente elitistas e excludentes e suas credenciais democráticas normalmente se baseiam no fato de que as leis por elas interpretadas foram produzidas por elites eleitas. Para que possamos superar essa "barreira de poder" presente nos governos representativos contemporâneos, é fundamental que realizemos uma abertura do poder a todos, em bases igualitárias, o que pode ser feito, segundo Landemore, por meio de um uso mais frequente do sorteio em nossas práticas políticas, a fim de que possamos edificar uma "democracia aberta", que reestruture o governo popular nos termos das exigências do século XXI. Tal paradigma poderá funcionar como uma lente crítica através da qual se pode olhar para as instituições existentes, mas também como um conjunto de diretrizes para conceber instituições novas ou, pelo menos, reformadas (LANDEMORE, 2020, p. 12). 


\section{SORTEIO E NÃO-DOMINAÇÃO: CONTRIBUIÇÕES DA "DEMOCRACIA ABERTA" PARA A REVITALIZAÇÃO DAS REPÚBLICAS CONTEMPORÂNEAS}

Em um contexto de crise da democracia representativa eleitoral, essa nos parece ser a ocasião propícia para a retomada de práticas há muito debatidas na história do pensamento republicano como modo de contornar - ou ao menos aliviar - as tensões decorrentes da desigualdade política, permitida ou fomentada por muitos governos representativos. É o momento de resgatarmos o sorteio, reintroduzindo-o em nossas práticas políticas em busca da concretização do ideal republicano da não-dominação.

De fato, analisando os limites práticos da democracia representativa brasileira a partir de elementos da tradição republicana, podemos identificar, pela predominância histórica do elemento aristocrático - o voto - em detrimento do elemento democrático - o sorteio - indícios de um atual desequilíbrio do "balanço do domínio", tal qual descrito por James Harrington em Commonwealth of Oceana. O anseio pela inclusão mais abrangente dos segmentos da população historicamente excluídos da participação política demanda, assim, uma alteração constitucional capaz de equilibrar o balanço do domínio ao marcante pluralismo da sociedade brasileira, cansada do domínio das elites eleitorais e partidárias, que permitem mais facilmente o surgimento de governantes autoritários e populistas.

Exemplos de um uso mais abrangente do sorteio, inspirados na tradição republicana, como os casos recentes da Assembleia nacional Constituinte da Islândia, em 2012, e da "Convenção Nacional de Cidadãos sobre mudanças climáticas", na França, em 2019, podem representar, portanto, importantes referências para o desenvolvimento de inovações democráticas no Brasil, fomentando a igualdade política e promovendo a mais do que urgente inclusão social.

Embora não preveja um arranjo institucional específico a ser adotado pelas democracias contemporâneas para a obtenção da maior "abertura" democrática por ela proposta, mas a experimentação local baseada nos contextos político-constitucionais de cada um dos governos a serem reformados, Landemore apresenta, por outro lado, um modelo central apto a ser utilizado como indicativo para as transformações dos governos representativos contemporâneos. Tal modelo baseia-se na formação de uma grande assembleia popular, composta por cidadãos selecionados aleatoriamente, integrada por um número entre 150 (cento e cinquenta) e 1.000 (mil) pessoas, que funcione, para todos os fins, como um "minipúblico" aberto, que se reúna por um longo período, que pode variar de alguns dias a até alguns anos. O objetivo de tais assembleias deve ser, em especial, a definição de uma agenda política para os representantes eleitos e até mesmo a realização de algum tipo de atividade legislativa. Em tais fóruns, com o uso das tecnologias atualmente 
existentes, como plataformas de crowdsourcing, os representantes aleatoriamente selecionados podem se comunicar com a população em geral, diretamente ou por meio de outros órgãos deliberativos. Essas assembleias, formadoras de "minipúblicos" abertos, assemelham-se, como observa a autora, a uma versão superdimensionada do júri criminal existente em diferentes países, que é uma das poucas instituições autenticamente democráticas que alguns dos governos representativos contemporâneos possuem (LANDEMORE, 2021, p. 12-13).

No Brasil, um tipo de assembleia de tal modo constituída poderia, por exemplo, estabelecer a pauta do Congresso Nacional e forçar a realização de debates sobre temas há muito adiados pelo parlamento, por tratarem de aspectos que não atendem diretamente aos interesses da oligarquia eleitoral dirigente.

No que diz respeito à estrutura partidária brasileira, dominada por uma elite burocrática e altamente exposta à luta de facções, conforme anteriormente apontado, para além das medidas analisadas pela perspectiva da "democracia aberta" (LANDEMORE, 2012), outras espécies de "lotocracia" ou "escolha randômica" podem ser pensados para o aprimoramento de nosso sistema eleitoral. O uso do sorteio realizado no procedimento de escolha do Doge na república de Veneza, por exemplo, pode ser um desses caminhos, ao trazer alguns aspectos capazes de iluminar a prática política brasileira.

Com efeito, diferentes qualidades do sistema de escolha do Doge de Veneza têm sido exaltadas em recentes estudos. Destaque-se, entre eles, o trabalho de Miranda Mowbray e Dieter Gollmann, intitulado Electing the Doge of Venice: analysis of a 13th Century protocol, que, ao analisar o processo de escolha do Doge sob uma perspectiva política combinada com elementos de tecnologia da informação, conclui que tal procedimento possuía algumas propriedades úteis passíveis de serem adotadas como protocolos para eleição de líderes em diversos segmentos. De fato, tal procedimento caracterizava-se por conferir oportunidades às minorias, ao mesmo tempo em que garantia que os candidatos mais populares tivessem maior probabilidade de vencer, oferecendo assim maior resistência à corrupção dos eleitores (MOWBRAY e GOLLMANN, 2007, p. 1).

Ora, na república de Veneza, o cargo de Doge era vitalício, mas a função não era hereditária. Como descreve Reybrouk, o processo de escolha do Doge, apelidado de ballota, em referência à bolinha utilizada para o sorteio, era extremamente complexo, sendo dividido em dez fases, que duravam cinco dias. Iniciava-se, no século XIII, com o Consiglio Grande (Conselho Geral), composto por quinhentos membros da nobreza. Cada conselheiro depositava na urna uma bolinha de madeira, com seu nome escrito, a ballota, enquanto o conselheiro mais jovem dirigia-se à Basílica de São Marcos e chamava o primeiro garoto entre oito e dez anos que encontrava. Ele era levado à sala do conselho, onde os conselheiros estavam reunidos em conclave, para ser o ballotino, 
responsável pelo sorteio das bolinhas ${ }^{7}$. O garoto sorteava o nome de trinta conselheiros, entre os participantes, seleção reduzida a nove em uma segunda rodada do sorteio. Esse grupo de nove cidadãos formava o primeiro comitê da eleição, que tinha por função chegar a quarenta nomes a partir dos nove, através de votação por maioria qualificada. $\mathrm{O}$ sistema estendia-se por um tempo, com a redução do comitê por sorteio e o posterior aumento pelo voto, alternando os métodos de escolha aleatória e eleitoral. Quando o comitê estava composto por 41 membros, eles finalmente escolhiam o Doge em conclave (REYBROUCK, 2017, p. 121-126).

Nesse processo, que durava em média cinco dias, a combinação do sorteio com as eleições permitia a vitória de um candidato popular, afastando ao mesmo tempo pretendentes com alta rejeição, sem, contudo, excluir as chances das minorias. Ao não reduzir de imediato o número de candidatos a um universo muito restrito, o processo prestava-se também a coibir a corrupção dos eleitores.

Como observa Reybrouck, a extraordinária longevidade da estabilidade da República de Veneza, que durou mais de cinco séculos até a sua dissolução, com a invasão napoleônica, deve-se muito ao engenhoso sistema da ballota. Sem o sistema de sorteio, a República teria de enfrentar muito mais disputas entre as famílias nobres, que compunham a aristocracia governante (REYBROUCK, 2017, p. 121-126).

Ora, o sistema partidário brasileiro sucumbe hoje exatamente pelas disputas internas de facções e pela precariedade do controle sobre as cotas de candidaturas de mulheres. $\mathrm{O}$ estabelecimento de um sistema misto, com a introdução do elemento sorteio, paralelamente às eleições, de modo semelhante ao sistema da ballota, da República de Veneza, talvez possa garantir a maior presença de minorias no processo de escolha dos candidatos de cada partido, diminuindo a influência das elites partidárias e, ainda assim, garantindo, pela permanência do elemento do voto, a escolha de candidatos populares.

Ao ser introduzido em substituição à simples observância de cotas para negros e mulheres, um sistema semelhante ao da ballota permitiria assegurar maior transparência ao processo de escolha das candidaturas e reforçar a filiação programática dos candidatos que, ao serem escolhidos parcialmente por meio de sorteios, deverão estar mais atentos aos termos dos programas dos partidos que serão por eles representados.

Além disso, a escolha mais morosa e procedimental das candidaturas pode favorecer a ampliação do espaço público de decisão, conforme ocorre, por exemplo, nas prévias de candidaturas dos Estados Unidos, servindo para manifestar, coletiva e individualmente, como destacam

\footnotetext{
${ }^{7}$ Procedimento semelhante vigorou no sistema criminal brasileiro para o sorteio dos jurados no Tribunal do Júri. A previsão do sorteio por um menor de dezoito anos só foi retirada do Código de Processo Penal com a reforma do procedimento do júri, ocorrida no ano de 2008.
} 
Mowbray and Gollmann sobre o protocolo de Veneza que os candidatos levam a sério sua responsabilidade de agir pelo bem da república caso sejam eleitos, e que, caso não sejam escolhidos, respeitarão o governo do Doge que for eleito (MOWBRAY e GOLLMANN, 2007).

\section{CONSIDERAÇÕES FINAIS}

Analisando o regime constitucional brasileiro a partir de elementos da tradição republicana, podemos identificar uma prática persistente de dominação política de amplos setores da sociedade por elites eleitorais, que se valem do obscurecimento de práticas essencialmente democráticas, como o sorteio, para perpetuar-se no domínio do aparelho de Estado, empreendendo uma verdadeira "oligarquização da democracia". Tal procedimento, que se utiliza de um recurso manifestamente reconhecido na história do pensamento político como de origem aristocrática - o voto - para o estabelecimento de uma "barreira de poder" destinada a afastar o povo da efetiva participação no governo, contou, para seu desenvolvimento, com a consolidação do eleitoralismo nos governos representativos contemporâneos, em clara oposição ao ideal republicano de "governo popular".

Esse eleitorialismo - que se difundiu pelo mundo a partir do modelo constitucional arquitetado pelos "pais fundadores" do governo representativo dos Estados Unidos da América tem por propósito promover uma neutralização política do povo ao estabelecer uma clara distinção entre os cidadãos ilustres, destinados a governar, e os eleitores, destinados a serem governados. Ao restringir a participação política dos cidadãos ao envolvimento episódico no processo eleitoral, tal sistema estreita substancialmente o conceito de cidadania, identificando o cidadão com o eleitor e limitando a sua participação ao silencioso e solitário momento do voto, em flagrante prejuízo ao princípio da igualdade política. Tomada em sua via estreita, a noção de representação decorrente dessa concepção eleitorialista tem por consequência o esvaziamento do espaço público, que passa a ser dominado de forma predominante pelas elites eleitas.

Em um contexto de crise da democracia representativa eleitoral, marcada por altos níveis de corrupção do sistema político, por dificuldades de superação das desigualdades sociais e pela incapacidade de inclusão das minorias, essa nos parece ser a ocasião propícia para a retomada de práticas há muito conhecidas no pensamento republicano como modo de contornar - ou ao menos aliviar - as tensões decorrentes da desigualdade política, tolerada em nosso regime constitucional pela inexistência quase absoluta da prática da seleção de cidadãos por sorteio - exceção feita à instituição do tribunal do júri. É o momento de se pensar em alterações constitucionais capazes de dar conta das exigências de inclusão de amplos setores da sociedade brasileira, levando a sério o princípio constitucional da igualdade, fundamento último da democracia. 
Nesse sentido, a formação de assembleias populares formadas total ou parcialmente por cidadãos aleatoriamente selecionados para mandatos de curta duração e com alta rotatividade, o uso de plataformas de crowdsourcing para coleta de proposições legislativas diretamente da população e a estruturação de "minipúblicos" destinados a estabelecer a agenda de debates públicos da nação, como sugere Landemore (2020), entre outras propostas, podem contribuir para a edificação de um regime misto em que a soberania popular seja levada a sério, com a consequente limitação do poder das elites eleitas.

No tocante ao sistema partidário brasileiro, em especial, o estabelecimento de um sistema misto, com a introdução do elemento sorteio de forma concomitante às eleições, de modo semelhante ao sistema da ballota, adotado historicamente pela República de Veneza, talvez possa garantir uma maior "abertura" democrática, com presença mais relevante de minorias no processo de escolha dos candidatos de cada partido, a diminuição da influência das direções partidárias e das lutas entre facções, além de assegurar maior transparência ao processo de escolha das candidaturas e maior fidelidade programática, ao estimular o debate de propostas em detrimento da escolha de pessoas.

Marcos teóricos recentes, como a proposta de "democracia aberta”, de Hélène Landemore, e exemplos concretos de um uso mais abrangente do sorteio, inspirados na tradição republicana, como os casos da "Assembleia Nacional Constituinte" da Islândia, em 2012, e da "Convenção Nacional de Cidadãos sobre mudanças climáticas", na França, em 2019, podem representar, nesse sentido, importantes referências para o desenvolvimento de "inovações democráticas" no Brasil, fomentando a igualdade política e promovendo o ideal republicano de não-dominação.

\section{REFERÊNCIAS BIBLIOGRÁFICAS}

ARISTÓTELES, Política (edição bilíngue). Lisboa: Vega, 1998.

BIGNOTTO, Newton. Problemas atuais da teoria republicana. In: Retorno ao republicanismo. São Paulo: Humanitas, 2004.

BOURICIUS, Terril. Democracy through multi-body sortitition: Athenian lessons for modern day. In: Journal of public deliberation, v. 9, n.1., 2013, art. 11.

BRUGGER, Bill. Republican theory in political though. London: Macmillan Press, 1999.

EHRENBERG, Victor. The Greek State, New York, W.W. Norton and Co., 1964.

GOMME, A.W. The population of Athens in the Fifth and Fourth Centuries B.C. Oxford, Oxford University Press, 1933. 
HANSEN, M.H. The Athenian Democracy in the age of Demosthenes - Structure, Principles and Ideology. Oxford: T.J. Press, 1991.

HARRINGTON, James. The Commonwealth of Oceana. Cambridge: Cambridge University Press, 1992.

HEADLAM, J. W. Election by lot at Athens. Norderstedt: Hansebooks, 2016.

LANDEMORE, Hélène. Open democracy: reinventing popular rule for the twenty-first century. Princeton: Princeton University Press, 2020.

MADISON, James; HAMILTON, Alexander e JAY, John. Os artigos federalistas. Rio de Janeiro: Nova Fronteira, 1987.

MANIN, Bernard. Principes du gouvernment représentatif. Paris: Flammarion, 2012.

NASCIMENTO, MILTON M. A farsa da representação política - Ensaio sobre o pensamento político de Rousseau. São Paulo: Discurso Editorial, 2016.

MONTESQUIEU. O Espírito das leis. São Paulo: Martins Fontes, 2000.

MOWBRAY, Miranda and GOLLMAN, Dieter. Electing the Doge of Venice: analysis of a 13th century protocol. In: www.hpl.hp.com/techreports2007/HPL-2007-28R1.pdf

PETTIT, Philip. Republicanism: a theory of freedom and government. Oxford: Oxford University Press, 1999

PITKIN, Hanna. The Concept of Representation. Berkeley: University of California Press, 1972.

REYBROUK, David. Contra as eleições. Belo Horizonte: Ed. Âyine, 2017.

ROUSSEAU, J.J. O contrato social. São Paulo, Martins Fontes, 1999.

Trabalho recebido em 02 de outubro de 2021

Aceito em 01 de novembro de 2021 